\title{
OPERATION PHAKISA: REFLECTIONS UPON AN AMBITIOUS MARITIME-LED GOVERNMENT INITIATIVE
}

\author{
Francois Vrë̈ \\ Stellenbosch University
}

\begin{abstract}
Operation Phakisa enjoys 'presidential' status as a project launched by and housed within the Presidency of the Republic of South Africa during the Zuma administration. Phakisa is a most ambitious project, which includes a prominent maritime component. The maritime focus functions as one catalyst for positioning South Africa as an international maritime player by 2030 and in the process speeding up national development through delivery of public goods, economic growth and jobs. Aiming to be an international maritime player supposes that foreign policy elements also feature in the project considerations. Launched in 2014, Phakisa's oceans leg now offers scope for scrutiny as mixed messages about its progress and failures routinely appear. The gist of the discussion is forward-looking, with Operation Phakisa's progress, failures and prospects to achieve government's 2030 maritime aims and objectives constituting the focus of the discussion. The study on which this article is based, found that Operation Phakisa's oceans leg depicts an impressive government ambition to exploit a new frontier, one reflecting progress and failures with promises of rapid big results being the most visible failure.
\end{abstract}

\section{Introduction}

New resource frontiers drew attention as growing demands for resources rose alongside enabling technologies to unlock demanding, but rich resource landscapes. Africa features prominently in the global resource debate, and its oceans form a major resource frontier within ongoing deliberations on exploring opportunities and promoting the blue economy. ${ }^{1}$ The oceans focus did not escape South African attention in the country's search for ways to boost a lethargic economy and shrink the growing void between promised and real service delivery. Hovering between the largest and second largest economy in Africa, adding a thriving oceans economy to South Africa's economic clout augurs well for the country's international, continental and national standing and a pathway for mitigating its growing economic woes. ${ }^{2}$

The ocean's economy hub of Operation Phakisa aligns with implementing South Africa's National Development Plan (NDP), and serves as an operational outlet for ways and means to access the country's oceans as a national resource. ${ }^{3}$ According to the official Phakisa webpage: 
Operation Phakisa is an initiative of the South African government. This initiative was designed to fast track the implementation of solutions on critical development issues. This is a unique initiative to address issues highlighted in the NDP 2030 such as poverty, unemployment and inequality.

The oceans sector of Operation Phakisa termed 'Unlocking the economic potential of South Africa's oceans' features alongside parallel initiatives to improve service delivery and speed up outputs to address societal needs, but one calling for real delivery and accountability. An Ocean Economy Lab supports the oceans focus of Phakisa to deliver on a range of maritime and marine-related sectors to support objectives of the NDP. Keeping in step with the Vision 2030 Summit and the NDP, South Africa's maritime road map envisages a future where "South Africa is globally recognised as a maritime nation" by $2030 .{ }^{4}$ The oceans leg of Operation Phakisa serves as a primary programme in pursuit of the said vision. Since its presidential launch in 2014, Phakisa's oceans project received its fair share of attention, criticism, complements and scrutiny, and entering year five in 2019, a review of progress and stasis is in order.

The following discussion draws on open literature, government reports and Phakisa-related websites, and proceeds along three themes covering the wider oceans debate and Operation Phakisa's oceans leg in particular. First, and in order to set Phakisa within the international oceans debate, the discussion reviews rising interests in the general oceans economy and the blue economy debate. Second, an outline of the objectives and expectations underlying Phakisa's oceans sector sets the scene for an assessment of Phakisa in 2019. The focus is on its marine sectors, how these support the drive for a blue economy, and matters of security as a basis for pursuing an ambitious maritime agenda. Third, some indicators on difficulties and shortcomings as well as progress are tendered before concluding with ideas on the way forward.

\section{Rising interests in the oceans economy}

The use of oceans in the pursuit of political, economic and social agendas reflects a history only second to that on land. Such use unfortunately entails a destructive side as well and one that coexists with drives and debates to utilise the oceans more responsibly. The twenty-first century brought renewed emphasis to the responsible use of ocean territories to unlock the overall economic potential tied up in the seas. Both the responsibility narrative as well as the opposing rights-based approach of unlimited use of the oceans now features alongside a greater emphasis on understanding the value of the ocean and a necessity to protect and conserve. ${ }^{5}$ Proponents of harnessing the ocean's potential for development must now contend with constraints imposed by a growing audience canvassing for the protection and responsible use of the ocean. The implied tensions are now characteristic of the ongoing oceans debate, which also seeped into Phakisa.

Oceans are subject to multiple pressures to gain access to more sovereign landscapes and gain traction for the multiple uses of ocean spaces, infrastructure expansion and resource access. ${ }^{6}$ Goal 14 of the United Nations' Sustainable Development Goals 
(SDGs) - Conserve and sustainably use the oceans, seas and marine resources for sustainable development - helps to focus international and national attention on the oceans with the sustainability adage a constant and clear conditionality for all. ${ }^{7}$ Holding political and socio-economic value and dire socio-environmental consequences responsible for getting it wrong, managing the costs of threats and conflict on and from the sea through co-operation or collaboration remains challenging to decision-makers. Interest groups nonetheless compete aggressively for access to larger ocean territories in order to gain navigation rights, extract resources, and hedge against future uncertainty, but now have to demonstrate responsibility, conservation and value for future generations.

Renewed emphasis on oceans as pathways to political economic, environmental and social delivery of public goods fosters contrasting perspectives on what the blue economy entails. Competitive views frame oceans in opposing ways "as areas of opportunity, growth and development, as well as threatened and vulnerable spaces in need of protection". ${ }^{8}$ The use of the concept 'blue economy' and its wider international profile continues and requires ordering to tone down the tendency to ignore or manipulate its deeper sustainability rationale. Integration with social inclusion, environmental sustainability and innovative business models counters reigning thought on crude exploitation of the oceans' economic benefits. ${ }^{9}$ One attempt to promote understanding flows from the UN's suggested outline of "marine-related economic development that leads to improved human well-being and social equality, while significantly reducing risks to the environment". ${ }^{10}$

Silver et al. (2015) move beyond mere endeavours of defining aspects of the blue economy to those of adding meaning and practice in different contexts. ${ }^{11}$ Regarding the utility of the oceans, four competing views emerge from their work: ${ }^{12}$

- Oceans as natural capital: The benefits vested in the ocean's natural infrastructure and biodiversity of the ecosystems of the ocean offer natural solutions with an economic value to be capitalised upon to promote the idea of a blue economy.

- Oceans as good business: Existing ocean sectors of business must continue, but simultaneously be held accountable for their roles through governance, marine science and monitoring. Extraction without accountability cannot continue.

- Oceans as integral to Small Island Developing States (SIDS): These entities argue that their livelihoods and developmental imperatives are so closely connected to the oceans that any threat to the oceans endangers their existence and requires partnerships and funding to pursue their objectives.

- Oceans as small-scale fisheries (SSF) livelihood: Accentuating humanoceans relations, SSF is also about poverty reduction, employment, empowering women and development. For SSF, ocean grabbing through privatisation is a threat as the oceans represent the common good, public property and a common heritage and not a benefit for the few over the many.

What becomes apparent from attributing meaning to the blue economy is that actors ascribe meaning to the concept that often resembles prioritising own interpretations of 
costs, benefits and interests, but not always captured within the idea of "nature as capital" and the responsibility to conserve. ${ }^{13}$ This is an ongoing tension in practices as well as continuing debates to uphold responsibility, sustainability and future use of the seas. At present, these competing views and practices (both current and future) co-exist with each reflecting its own adherents. The underlying tension resides in more immediate gain and profit and the holding of a longer view based on sustainability and lower impact upon the oceans for the common good. Caught within these tensions are the SIDS and SSF agendas with their almost existential immediate and longer-term interests in healthy and productive oceans.

Optimism about the potential tied up in oceans as good business thus blends with concerns about ocean health and the underlying notion of what blue economy practices entail. However, balancing the ocean economy as a productive system with environmental and sustainability imperatives keeps the productive elements of the blue economy in equilibrium. ${ }^{14}$ Barbesgaard for example refers to the "everyone wins" perception as opposed to the negative impact of ocean grab on conservation and restoration of ocean resources to mitigate climate change that cuts across all aspects promoting healthy and productive oceans. As opposed to the well-documented landward drive for resources and territory, the same maturity of debates unfortunately does not ring true for the oceans. ${ }^{15}$ The destruction on land caused by the quest for resources to sustain growth, prosperity and development is known and well researched. The debate on using the oceans as the remaining $70 \%$ of the earth's surface for business purposes holds a negative and destructive side for those carving out a livelihood from the oceans. ${ }^{16}$

Findlay differentiates between an oceans economy as a phenomenon and a blue economy where sustainability is the guiding intelligence. He is of the view that "a sustainable (or blue) economy only emerges when economic use is in balance with long-term capacity of ocean ecosystems to support this activity and remain resilient and healthy". ${ }^{17}$ Findlay refers to a number of alternatives to govern the inherent strains with specific reference to South Africa's turn to the oceans economy, namely -

- ocean systems monitoring and research;

- development of data systems, information and knowledge;

- marine spatial planning to mitigate conflict through trade-offs;

- creation and efficient management of marine protected areas in line with international targets; and

- regulation, compliance monitoring and enforcement.

Landward practices of ever-growing extraction with limited or scant responsibility towards sustainability and environmental damages should not underpin any oceans economy model. A balance between profits that support ecological integrity for the benefit of future generations is a simple but critical assumption for understanding what the commitment to blue economic thought and practice entails. Exploiting the oceans economy and heeding blue economy imperatives form part of a competitive paradigm influencing ongoing debates. Governments nonetheless push on with their preferred 
ideas on exploiting ocean landscapes perceivably under the blue growth-good business label of which the oceans leg of Operation Phakisa is one example. Given where South Africa now finds itself within the larger debate and its particular oceans use policies embedded in Phakisa's dominant oceans focus, decision-makers and practitioners must navigate the trajectory from an oceans economy to a blue economy.

\section{Disentangling Operation Phakisa}

Phakisa's oceans sector resonates with the oceans as good business, as natural capital and the interests of small fisheries as reflected under the Oceans Economy Laboratory of the overall project. In essence, Phakisa is steeped in the adoption of a cultural transfer of a method introduced by Malaysia to expedite elements of economic transformation. ${ }^{18}$ Contrary to what comments and reporting often reflect, the oceans focus of Phakisa is not the sole outcome of this cultural adaption practice. It sits alongside sister initiatives to address critical areas of South Africa's NDP collectively. Health, mining, education, the chemical and waste economy, the oceans, biodiversity and agriculture, and land reform are parallel constituent elements of Operation Phakisa with delivery plans for each. ${ }^{19}$

The South African concern with harnessing the ocean economy entails deriving socio-economic benefits from safe and secured resource extraction from the 1,5 million $\mathrm{km}^{2}$ exclusive economic zone (EEZ). A recent oceans economy and sustainability workshop on 10 April 2018 at Wits University in Johannesburg, for example, emphasised sustainability and environmental protection in its opening slides. However, the main narratives remained centred on the oceans as a business sector for exploitation by way of aquaculture, oil and gas extraction, marine transport and manufacturing with marine protection services and ocean governance collectively serving as primary delivery areas. ${ }^{20}$ Inherently, sustainability, responsibility and the future do not feature as saliently as one would expect and point to a more general predisposition that the blue economy concept has no explicit standing of its own.

Irrespective of how salient the blue economy features, five criteria underpin the selected growth and delivery areas in the Operation Phakisa Ocean Economy Initiative. These criteria point the potential contributions of the said delivery areas to the gross domestic product (GDP) and job creation, relevance to the marine eco system, geo-political, security and environmental implications, institutional and logistical capacity requirements for the growth area followed by novelty. ${ }^{21}$ Of importance and probably indicative of a concern with not failing to capture maritime potential and opportunities on offer, industry, civil society, academia and labour collaborate to operationalise the four delivery areas. In a way, South Africa's government views Phakisa's oceans sector as a problem-solving initiative to address regression in socio-economic growth, service delivery and uplifting society. The latter feeds back into how the oceans serve as a 'new' landscape to enhance inclusive growth and development, but in a manner that guarantees sustainable ocean landscapes. ${ }^{22}$ Phakisa's oceans initiatives now reside between two sets of pressure: 
- first, promises and premises pledging quick results and growth from accessing the ocean economy through oceans grab and competitive exploitation; and

- second, the responsible sustainable use of the ocean vested in the blue economy rationale suggests a longer-term and more precarious way of tying the country's oceans into the NDP for growth and development.

The first seems prominent and leading the way; the latter more declaratory and less prominent than one would expect, but bringing the oceans economy into the overall economic fold is now a new South African reality.

The road map for $2030^{23}$ shows a number of goal posts for South Africa's envisaged future maritime standing. Each goal has a Phakisa oceans economy footprint framed by progress up to date. The objectives tie in with core ideas of securing the oceans landscape for Phakisa and in a way harbour elements of maintaining a blue economy and fostering international recognition. ${ }^{24}$ While the safety and security narrative is explicit, the security of the environment and future use and sustainability feature less prominent, and this is a concern. Buzan $(1991)^{25}$ points to the difficulty of securitising environmental security as an existential threat, and in 2019, Bueger again picked up on the environmental debate as "the forgotten dimension" with reference to the oceans. ${ }^{26}$ In essence, the entrapment is one of convincing decision-makers that environmental threats are on a par with military, economic and political threats with the latter still being deemed existential and familiar in terms of understanding and responses than. Taking this to the oceans security debate could well hold difficulties of its own. It remains to be seen whether South Africa has bridged the divide to bring environmental concerns fully into the Phakisa fold to step more fully into the blue economy debate.

The connection between Phakisa, safety and security, and South Africa's 2030 maritime roadmap finds expression in normative linkages indicated in the road map's high-level objectives: ${ }^{27}$

- Objective 2. We have an enabling governance framework for the maritime sector by closing down jurisdictional gaps in law, protection enforcement and prosecution.

- Objective 4. We utilise our resources sustainably and protect our natural resources in the EEZ by research-driven conservation of marine resources and reducing pollution levels.

- We have national, regional and international presence and recognition to strengthen South Africa's position in the international maritime space. ${ }^{28}$

- Objective 7. We prioritise safety and security and military protection within and beyond our EEZ through innovative opportunities, collaboration with Africa, investing in safety and security, maintaining safety and security standards, technologies and research to promote safety and security. 


\section{A blue economic future: Raising the threshold for Phakisa}

The rush to share in the economic potential of the oceans implies keeping in step with competitors who hold similar aspirations. Overall, one finds a propensity for some power grab to control marine resources for global objectives of feeding growing populations featuring alongside poverty reduction to ulterior motives claiming to save the environment. ${ }^{29}$ Smaller debates feature on how ocean-related economic and environmental matters compete with 'blue grabbing', which potentially mitigates interests and rights of people. Capital growth still comes first and in the ensuing competition, ecological and social costs suffer.

Emerging research on blue growth and social impact is not yet widely known and/or convincing. Extraction and exploitation drives directed by own interests still appear to outmanoeuvre climate and conservation matters. ${ }^{30} \mathrm{~A}$ win-win reality remains uncertain for climate investors and coastal communities as blue growth drives remain contested and exposed to trade-offs between capital for blue growth and that of unsustainable practices driven by big business and profits. Claims of a commitment to a blue economy require additional understanding of what is at stake. Engaging in an oceans economy founded on blue principles supposes different pathways demonstrating a greater responsibility to invest in the sustainability with a strong consensus on protecting the future.

South Africa shows a well-articulated commitment to develop its oceans economy. Turning to the imperatives of a blue economy, the latter is not explicit in South Africa's focus on the oceans economy. A search for blue economic commitments in Phakisa-related documents uncovers the absence of an overt blue economic rationale in the oceans leg of Phakisa. The following documents and reports on Phakisa lack explicit commitment or references to the pursuit of blue economic principles or practices: ${ }^{31}$

- the presidential address in Durban at the launch of Operation Phakisa dated 15 October 2014;

- the earlier-mentioned maritime road map (2016) to position South Africa as a recognised international maritime player by 2033;

- the Oceans economy Review Workshop of 15 October 2015;

- Operation Phakisa - 'Unlocking the oceans economy through aquaculture' dated October 2016;

- Operation Phakisa on South Africa's oceans economy in its advertising of facilities and capacities of South Africa as the top oceans economy on the African continent;

- Portfolio Committee Briefing: Feedback by the Department of Agriculture, Forestry and Fisheries (DAFF) on aquaculture of Operation Phakisa oceans economy dated 24 October 2017;

- Phakisa's Oceans Economy Summary Report dated September 2017; and

- An oceans economy and sustainability workshop (10 April 2018) although the workshop title suggested sustainability as the focus. 
The collective drive to harness South Africa's ocean landscape and direct its economic potential towards better governance and supply of quality public goods to society is encouraging and on the surface well mapped, structured and located at the highest political office. ${ }^{32}$ While the absence of explicit blue economy commitments remains an element of concern, the oceans sector of Phakisa continues to grow with 2019 being the time marker for a next review on progress and stasis by the Office for Programming, Monitoring and Evaluation in the Presidency.

\section{Overall progress with Phakisa's oceans economy leg}

The Department for Planning Monitoring and Evaluation (DPME) in the Presidency updates progress on Operation Phakisa with government departments and agencies responsible for different sectors of Phakisa's oceans leg. Departments of Transport, Minerals and Energy, Environmental Affairs and Agriculture, Fisheries and Forestry feature prominently, with the Departments of Defence and Safety and Security less prominent, but not unimportant. The latest updates show detail within the different initiatives as reported by March 2019. It is unclear whether the progress in fact reflects 2019 data, but from the available information one can discern progress and stasis.

Table 1. Progress report on Phakisa's oceans leg $^{33}$

\begin{tabular}{|l|c|c|c|}
\hline \multicolumn{1}{|c|}{ Work stream } & $\begin{array}{c}\text { Focus area } \\
\text { activities }\end{array}$ & \% completed & \% on time completions \\
\hline Aquaculture & 1742 & 37 & 18 \\
\hline Offshore oil and gas & 288 & 97 & 20 \\
\hline Marine protection and governance & 275 & 72 & 20 \\
\hline Marine transport and manufacturing & 308 & 20 & 32 \\
\hline Coastal and marine tourism & 117 & 32 & 25 \\
\hline
\end{tabular}

Table 2. On marine protection and governance progress ${ }^{34}$

\begin{tabular}{|l|c|c|}
\hline \multicolumn{1}{|c|}{ Initiative } & $\begin{array}{c}\text { Due } \\
\text { activities }\end{array}$ & $\begin{array}{c}\text { \% completion of due } \\
\text { activities }\end{array}$ \\
\hline Accelerate capacity building & 34 & 15 \\
\hline Enhance coordinated enforcement & 56 & 89 \\
\hline Establish coastal information system for management & 39 & 71 \\
\hline Oceans and coastal pollution monitoring & 35 & 80 \\
\hline Marine Protected Area (MPA) representative network & 25 & 57 \\
\hline $\begin{array}{l}\text { MPA/Marine Spatial Planning (MSP) discovery, research and } \\
\text { monitoring programme }\end{array}$ & 30 & 84 \\
\hline Marine spatial planning & 56 & 87 \\
\hline
\end{tabular}


Tables 1 and 2 above indicate that the working streams (other than marine protection and governance, and oil and gas) are less successful although Pretorius reported in 2017 that, at the time, the oil and gas working stream was more successful than the rest. ${ }^{35}$ Overall, the results in 2017 and the early data reported for 2019 both portray two successful working streams that do not augur well for Phakisa as a delivery mechanism for big and fast results in support of the NDP.

\section{Security first: Reviewing safety and security indicators for South Africa's coastal waters}

Phakisa's oceans sector requires a stable governance setting to fortify the exploration and utilisation of minerals, aquaculture, marine protection areas as well as fostering maritime commerce and manufacturing. South Africa's current maritime security governance profile appears to be stable given the perceived absence of piracy, robbery and attacks on vessels at sea or in anchorages. However, the scope of developments and contributions from ocean activities calls for closer scrutiny. A successful ocean-based economy rests upon safety and security, infrastructure, and dense but secured multi-use of marine and maritime resources all of which attract legitimate and illegitimate state and non-state actors in what Shemella calls the maritime violence ecosystem. ${ }^{36}$ Attractive and growing economic opportunities in coastal zones (on and offshore) reinforce domestic and international migration patterns of people, business and related industries but unfortunately local, national and transnational criminal actors as well. Crimes with maritime tentacles grow with robberies at sea, human smuggling, stowaways, narcotics, black market activities, and international crime networks entering the landscape.

The Ibrahim Index on African Governance (IIAG) and the Stable Seas Index (SSI) offer a more nuanced outlook on the security landscape within which Phakisa resides. The IIAG sets South Africa's 2019 Landward Safety and Rule of Law count at 66,7/100. The count stems from indicators on Rule of Law (90,2), Transparency and Accountability $(57,4)$, Personal Safety $(33,5)$ and National Security $(85,7)$. Overall governance for South Africa stands at 68/100 with Participation and Human Rights, Sustainable

Economic Opportunity and Human Development being the other three measurement categories.

As for the focus upon economics - the IIAG reports as follows for South Africa. Overall, 65,1/100, and for the constituent indicators the counts are: Public Management 62,6 and Rising; Business Environment 67,6, but deteriorating; Infrastructure at 65,9 and slowing down and deteriorating, and the Rural Sector at 64,1 and bouncing back. The economic indicators appear average to good. Adding a successful and well-governed oceans economy to the mix could well foster even better economic prospects. When compared with the Stable Seas Index ${ }^{37}$ for South Africa's overall 2019 maritime security governance, the count stands at 66/100, underpinned by the following counts: 
Table 3. SSI counts for South Africa

\begin{tabular}{|l|l|}
\hline International co-operation & 94 \\
\hline Rule of Law & 62 \\
\hline Enforcement & 52 \\
\hline Coastal welfare & 48 \\
\hline Blue economy & 44 \\
\hline Fisheries & 74 \\
\hline (Absence of) piracy & 100 \\
\hline Illicit trade & 44 \\
\hline Illegal mixed migration & 74 \\
\hline
\end{tabular}

Both indexes portray counts that support arguments for a relatively stable security environment to pursue marine and maritime-related objectives. The stability counts support the premise that a stable safety and security environment on land and at sea permits the pursuit of viable and constructive political, economic and social agendas. ${ }^{38}$ The same premise applies for pursuing such agendas at sea. ${ }^{39}$ For South Africa, landward security as it now stands, is not a key catalyst for insecurity at sea.

The safety and security conditionality portray concerns for South Africa's oceans initiative to bring its oceans economy to fruition. Although political expectations for Phakisa regarding growth, job creation and gross national product (GNP) contributions are optimistic, not all indicators support the optimism. ${ }^{40}$ Transparency and accountability as well as personal safety and security indicators of the IIAG for South Africa show average counts. Deeper exploration of each highlight uncovers more concerns. According to the IIAG, Rule of Law is deteriorating, so is transparency and accountability. Personal safety achieved low and weakening counts. Only national security indicators in the IIAG show an improving trend.

Not all SSI counts augur well for Phakisa. For the blue economy, the absence of oceanic oil and gas discoveries is a major detractor given the disappointing progress in adding local oil and gas to its blue economy mix. On a positive note, Total's 2019 discovery of significant gas deposits south of Mossel Bay may alter this variable given a potential one billion barrels of wet gas.. The Total discovery could be a game changer in the country's oceans economy that suffers from the absence of energy-based contributions to the mix. ${ }^{41}$ The tourism count is average, and is suppressed by a perceived tourism-climate change nexus impacted by doubt about South Africa's capacity to deal with climate change while crime levels on land add to lower tourist counts. Illicit trade in South African waters portrays negative counts informed by unsatisfactory countering of smuggling in wildlife and black market pharmaceuticals. Maritime enforcement falls victim to the imbalance between territorial size, coastline length and assets in order to police such a large geographic maritime territory. For mixed migration, maritime 
trafficking in young men gang-pressed into the fishing industry is a concern and militates against the encouraging counts of other indicators. As for stowaways, Protection \& Indemnity insurers for example flagged South Africa (Durban in particular) as high risk with a growing and disturbing number of stowaways found.$^{42}$ Collectively, enforcement, illicit trade, migration and stowaways highlight security governance, or some voids in the overall governance architecture.

\section{Environmental concerns: Prioritising environmental governance in support of maritime security}

Environmental sustainability dovetailing with stakeholder interests is vital to promote a healthy and productive ocean ecosystem. Practices that do not conform to the blue and green economy concepts promote uncertainty about sustainable and responsible extraction of living and non-living resources. National interests driven by oceans grab, the oceans as business, and capital open for exploitation by all sit uncomfortably alongside responsibility, conservation and restoration of ocean resources as underlying notions of a sustainable economy. South Africa must heed the international shift in how to harness the full potential contained in the country's marine-based economy, but in a responsible and sustainable manner. Bringing in sustainability and responsibility envisages: 43

- social and economic benefits for future generations;

- restoring, protecting and maintaining natural capital vested in ocean landscapes; and

- clean technologies, renewable energy and circular economy principles.

The task of developing an overarching, integrated ocean governance framework for the sustainable growth of the ocean economy falls under the Marine Protection Services and Ocean Governance working streams. Several initiatives were set out and eventually achieved, albeit not all on time, or in progress: ${ }^{44}$

- Development and implementation of an overarching governance plan by March 2015. The plan entails the protection of the ocean environment against illegal activities and to promote its multiple socio-economic benefits with results by 2017 .

- The delivery of a National Marine Spatial Planning Framework in order to enable a sustainable ocean economy by December 2015.

- Progress on working towards an Oceans Act and a draft Oceans Bill in 2015. The Oceans Act will provide a clear foundation for marine spatial planning.

Turning to the economic value chain of the oceans, Phakisa's architects in fact claim to promote responsible and sustainable ocean use as opposed to unmitigated and destructive ocean exploitation. ${ }^{45}$ This stands in contrast to the "brown business as usual model" 46 of free extraction and waste dumping without due consideration of its impact. With the South African Department of Environmental Affairs (DEA) as the lead de- 
partment for security and governance within the maritime leg of the Operation Phakisa programme, a symbolic emphasis on concerns with environmental caution appears to have taken root. Findlay, however notes that the delivery areas still resort under their functional government departments. ${ }^{47}$ This risks dysfunctional national departments, interdepartmental tensions and eventually neglect and/or ignorance of the objectives to sustain growth and to maximise socio-economic benefits and environmental protection at sea. Crucial to environmental concerns are matters that endanger or pressure notions of prevention, sustainability, healthy productive oceans and preserving the oceans for future generations. The latter requires operational governance capacities to enforce sustainability and environmental protection. This is perhaps the single most important vulnerability in terms of not moving from statements of intent to actions.

Policy documents commit state departments and agencies of Phakisa to the environment-sustainability nexus through the National Framework for Marine Spatial Planning in South Africa (of 26 May 2017), and Marine Protected Areas (MPAs) with 22 MPAs set out under Phakisa's MPA network. The MPAs entail a holistic approach to lower the impact of industrialisation of the ocean and not only conservation of fish and other living organisms. The MPAs do not provide for some critically endangered species, although they hold indirect advantages related to tourism, social upliftment, education and cultural as well as historic preservation. A further concern is weak enforcement and governance in terms of ensuring environmental protection and its sustainability nexus. ${ }^{48}$ Uncertainty remains whether the practical execution conforms to the blue concept as the review workshop document of 15 October 2015, for example, reflects no reference to sustainability in the execution of the Phakisa programmes, neither does the presidential feedback of 8 April 2016. Both report on hard challenges of infrastructure progress, outputs and investments that accentuate the oceans as good business akin to oceans grab. ${ }^{49}$ This casts uncertainty over the aquaculture, offshore oil and gas, marine protection and governance, marine transport and manufacturing, coastal and marine tourism, small harbour and coastal land development sectors residing within the oceans economy lab of Operation Phakisa with the state departments mentioned earlier as the responsible executing agencies.

Government's fixation with extraction from and transport via its ocean lines of communication contradicts declaratory commitments to protect the environment. ${ }^{50}$ Environmental protection is the difficult ambit of using the oceans for wealth creation and public service delivery. Lowering of standards to protect the environment does little to instil confidence that Phakisa's oceans focus prioritises environmental concerns. ${ }^{51}$ It is not geographically defined or containable within the national ambit to prevent or control, but rather networked into international co-operation and thus partially in the foreign policy field. Similarly, global trade, lower Foreign Direct Investment, glut of shipping capital, and commodity price volatility all influence and make for uncertainty about the predicted success of Phakisa's oceans economy. In essence, the pace and projections of what the turn to offshore assets offers to grow the economy and address socio-economic threats and vulnerabilities, are set within an international system that too often opposes Phakisa's imposed optimism. 
Finally, Phakisa's oceans focus faces growing resistance to exploiting natural capital as contained in the ocean's resources and inherent natural contributions to regulate climate. Short-term economic and political gains under the banner of growth and service delivery have to contend with growing societal opposition to encroachment upon environmental concerns. ${ }^{52}$ Mineral exports through shipping and oil and gas extraction underpin Phakisa's success, but these sectors operate under conditions of uncertainty and increasing environmental scrutiny. Unfolding corruption and state capture revelations involved in megaprojects, such as Phakisa, are a real and dangerous concern with Southwell describing this as pollution of South African politics and the seas. ${ }^{53}$ It remains to be seen whether Phakisa escapes the vast state capture and corruption networks now being uncovered by the Zondo, Nugent and Mpati Commissions of Inquiry.

\section{Capacity to maintain the rule of law}

Shemella distinguishes between capability and capacity where the former supposes an entity or agency is able to do something once, while capacity supposes employment of a certain capability in a repeated and consistent manner over time to achieve a set outcome. ${ }^{54}$ The capacity to extend maritime security governance entails a comprehensive set of activities to root out or mitigate even minor transgressions at sea alongside major threats from terrorism, piracy and transnational crime syndicates. Particular threats listed by Phakisa's marine protection and governance leg are marine protected species in MPAs, illegal fishing, prevention of and combatting pollution, piracy and human trafficking, effluence discharge and waste dumping at sea. ${ }^{55}$

The South African Police Service (SAPS) has a sea border unit, but one almost devoid of capability or capacity to operate beyond South African harbours in spite of its obligation to police territorial waters up to 12 nautical miles (nm). By February 2018, SAPS still had no operational sea-going capability to deal with threats from the sea within its area of responsibility and through its sea border unit beyond proposals on how to police harbours - small harbours in particular. Fact remains that any threat from the sea beyond harbours had become the de facto responsibility of DAFF with one offshore and three inshore protection vessels dedicated to fisheries protection and vessels of the SA Navy. ${ }^{56}$ Leaving aside some progress in acquiring new navy vessels for inshore patrolling and hydrographic services, no credible capacity-building programme is visible to support Phakisa's oceans leg at sea with enforcement. ${ }^{57}$

Physical prevention and enforcement must align with governance through oversight of how departments execute policies and implement strategic plans. Several departments are involved in the different growth and delivery areas presuming departmental oversight, including parliamentary oversight. South Africa's political governance is currently entwined in clientism, corruption, mistrust and ad hoc arrangements that cloud the turn to an oceans economy - which is firstly a political project of the ANC government. ${ }^{58}$ The Departments of Agriculture, Forestry and Fisheries, ${ }^{59}$ of Minerals and Energy, of Transport, of Environmental Affairs and of Defence and Police all constitute responsible departments within the Phakisa ocean economy leg that resort under oversight committees of the SA parliament. All are monitored as Phakisa cannot 
proceed unchecked and override caution for the sake of commercial exploitation. One perception that remains is that Phakisa's oceans drive is about corporate profits to the detriment of people, the environment and sustainability, and possibly already a victim of state capture ${ }^{60}$

\section{Mapping progress and stasis in Phakisa's oceans sector}

Turning to the oceans as demonstrated by Phakisa's oceans programme is encouraging. Supported by a roadmap leading towards 2030 to position South Africa as an internationally recognised maritime player, this augurs well for the future. Both initiatives set the country within the oceans debate and imply that South African decision-makers must negotiate the interplay between international dialogue and practical service delivery to its citizens. ${ }^{61}$ In essence, this is about thinking about a different problem setting, which includes mastering ocean debates and practical contributions, ways to adjust existing structures and collaborate with multiple stakeholders to turn from declaratory statements to operational matters, and ultimately outputs as service delivery of public goods.

In spite of criticism, the oceans focus continues, and Phakisa draws in initiatives that prefer to be associated with Phakisa. As a conceptual umbrella, Phakisa's oceans programme stimulates a latent economic landscape with much potential, but it is weakly utilised, regulated and protected. It is thus a question of whether the South African government can unlock the ocean's potential by negotiating the required partnerships, bureaucratic obstacles and reigning political weaknesses of questionable governance architecture. International engagement is key and explicitly mentioned in the 2018-2019 Strategic Plan of the Department of International Relations and Cooperation (DIRCO) to engage international partners in the furtherance of the oceans economy. ${ }^{62} \mathrm{~A}$ simultaneous requirement stems from setting up local public-private partnerships (PPPs) to augment the narrow government and semi-state profile of Phakisa's current approach to unlock the country's oceans economy.

As a normative framework, Phakisa's oceans focus is inclusive and maps out clear outcomes. ${ }^{63}$ From the outset, government cultivated active participation by diverse actors - government, non-governmental, industry and academia - to bring about the attributes of clustered governance. ${ }^{64}$ Declared but questioned support by a secretariat and inter-ministerial committee promises to consolidate management as opposed to scattered or fragmented management of individual departments. ${ }^{65}$ While the presidency reports on progress and departments concentrate on their designated delivery areas, the inter-ministerial committee consolidates the overall effort as a vertical conduit for the national departments and their agencies. Phakisa also advances human capacity development, job creation, research, technology and innovation that collectively hold potential to promote ocean governance. ${ }^{66}$

On a more cautionary note, big, fast results from South Africa's drive to bring its oceans economy into line, are not running smoothly. First, a general analysis questions the use of the the Malaysian model as it does not translate to a good fit. Upon closer scrutiny, the designated governance modes of efficiency presumed by the Malaysian 
model diverge from South Africa's governance sector, which is increasingly characterised by corruption, and personalised institutional ravages taking their toll. Governance structures have become ineffective in too many critical areas related to Phakisa's departmental-based oceans sector to set in place capable steering committees and overcome legislative obstructions. ${ }^{67}$ The extent to which Phakisa rests on big, fast results through a competent public sector, South Africa's failing public governance is of great concern. ${ }^{68}$

Slow policy development, a lack of leadership, weak institutional arrangements, and weak stakeholder communications could well weaken interest in the Phakisa project. This is supported by limited progress in all the areas with the oil and gas working stream perhaps the exception. Slow progress with aquaculture, protection and governance, transport and manufacturing makes for pessimism, given their limited or less than encouraging on-time achievement of their objectives. ${ }^{69}$ Together with political and extensive bureaucratic problems, Phakisa could well render an unattractive business environment for local and international private partnerships, particularly the absence of integrating Phakisa more aggressively into foreign policy initiatives. Developing a secure and growing oceans economy requires public-private ventures at home and with international business entities, as well as governments, elements still showing room for improvement within the Phakisa ambit. ${ }^{70}$ Their absence points to a probable loss of confidence in working with South Africa in general and within the oceans economic sector in particular. Underlying this is the failure of South African government departments and bureaucrats to attract and orchestrate such co-operation in the upcoming field of oceans governance and the blue economy to interface the country's oceans economy more fully with the country's landward economic fabric. 


\section{ENDNOTES}

${ }^{1}$ J Schubert, U Engel \& E Macamo. "Introduction: Boom and bust: Extractive industries

and African states in the twenty-first-century". In Attri, VN \& BohlerMuller, N (eds), The blue economy handbook of the Indian Ocean. Pretoria: Africa Institute of South Africa, 2018, 1.

${ }^{2}$ Statistics South Africa. "A tale of three economies in Africa”. 20 February 2017. $\leq \mathrm{http}: / /$ www.statssa.gov.za/?p=9583 $>$ Accessed on 13 April 2019.

3 National Science and Technology Forum. "Understanding the context of the National Development Plan (NDP)". 2017, 3. < http://www.nstf.org.za/ wp-content/uploads/2017/10/The-NDP-part-1-to-4-Sep2017-06.pdf $>$ Accessed on 17 January 2019.

${ }^{4} \mathrm{~N}$ Funke, M Claassen, K Nortje \& R Meissner. A research, innovation and knowledge management road map for the South African maritime sector: Charting a course to maritime excellence by 2030. Report no. CSIR/NRE/WR/ ER/2016/0044/A. Pretoria: Council for Scientific and Industrial Research, 2016, 13.

${ }^{5}$ T Edvardsen. "The future ocean economy". Introductory talk by Marine Socio-ecological Systems (MSEAS), Brest. 30 May 2016. < https:/www. youtube.com/watch?v=yXH9PSIOpFY > Accessed on 15 March 2020.

${ }^{6} \mathrm{~J}$ Kraska. Maritime power and the law of the sea. Oxford: Oxford University Press, 2011, 6-7; J Przedrzymirskal, J Zauchal, D Depellgrin, et al. "Multi-use of the sea: From research to practice". SHS Web of Conferences 58. GLOBMAR 2018. 2-3.

${ }^{7}$ MJ Spalding. "The new blue economy: The future of sustainability". Journal of Ocean and Coastal Economics (Special Issue Oceans and National Income Accounts: An International Perspective) 2/2. 2016. 3.

${ }^{8}$ M Voyer, G Quirk, A McIlgorm \& K Azmi. "Shades of blue: What do competing interpretations of the blue economy mean for oceans governance?" Journal for Environmental Policy \& Planning 20/5. 2018. 596.

${ }^{9} \mathrm{~N}$ Verma. "Integrating a gender perspective into the blue economy". In Attri \& Bohler-Muller op. cit., p. 103.

${ }^{10}$ United Nations. Blue economy concept paper. Sustainable Development Goals Knowledge Platform; 15 January 2014, 3.

${ }^{11}$ J Silver, N Gray, L Campbell, L Fairbanks \& R Gruby. "Competing discourses in international oceans governance". Journal of Environment and Development 24/2. 2015. 151 .

${ }^{12}$ Ibid., pp. 143-149.

${ }^{13}$ Ibid., p. 139.

${ }^{14}$ VN Attri. "The blue economy and the theory of paradigm shifts". In Attri \& BohlerMuller op. cit., pp. 28-29. 
${ }^{15}$ M Barbesgaard. "Blue growth: Saviour or ocean grabbing?" The Journal of Peasant Studies 45/1. 2018. 131.

${ }^{16}$ Ibid., p. 142.

${ }^{17}$ K Findlay. "Phakisa and unlocking South Africa's ocean economy". Journal of the Indian Ocean Region 14/2. 2018. 249.

${ }^{18}$ U Engel. "The blue economy and Operation Phakisa”. In Shubert, J, Engel, U \& Macamo, E (eds), Extractive industries and state dynamics in Africa. Routledge Studies in African Development. London: Routledge, 2018, 60.

${ }^{19}$ Ibid., p. 61.

${ }^{20}$ A Share. Sea Change: Socio-Economic \& Sustainability Goals in National Ocean Strategies“"Workshop Presentation on Operation Phakisa, Oceans Economy and Sustainability Workshop. Oceans Economy Secretariat, place, 10 April 2018.

${ }^{21}$ N Bohler-Muller. "South Africa's ocean economy and Operation Phakisa”. In Attri \& Bohler-Muller op. cit., p. 237.

${ }^{22}$ E Owusu-Sekyere. "Achieving sustainability in the context of the blue economy". In Attri \& Bohler-Muller op. cit., p. 84.

${ }^{23}$ Funke et al. op. cit.

${ }^{24}$ Funke et al. op. cit., pp. 1, 15, 39-41.

${ }^{25}$ B Buzan. People states and fear: An agenda for international security studies in the post-cold war era. 2nd ed. London: Harvester Wheatsheaf, 1991, 129-130.

${ }^{26}$ SafeSeas. "Environmental crime at sea: The forgotten dimension". 20 October 2019. $<\underline{\text { http://www.safeseas.net/environmental-crime-at-sea-the-forgotten-dimen- }}$

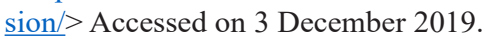

${ }^{27}$ Ibid., pp. 39-41.

${ }^{28}$ Although an SADC (Southern African Development Community) maritime security strategy (confidential) is in place since 2011, reality leans towards co-operation with international (non-African) partners on maritime security and related affairs. This leaning is visible in annual or biannual maritime exercises with Brazil, China, France, Germany, India and Russia, but not with SADC or African partners.

${ }^{29}$ Barbesgaard op. cit., p. 130.

${ }^{30}$ Ibid., p. 143.

${ }^{31}$ Department of Monitoring, Planning and Evaluation. “Oceans Economy Lab”. N.d. $<$ https://www.operationphakisa.gov.za/operations/oel/pages/default.aspx $>$ Accessed on 11 December 2019.

${ }^{32}$ Phakisa is an interdepartmental initiative, but its progress resides with Department for Performance, Monitoring and Evaluation (DPME) in the South African Presidency. The NDP outlines Phakisa as a mechanism to implement the NDP with the oceans leg mentioned as one of the implementing projects for delivery purposes, which coincides with the 2030 time line to position South Africa as an international maritime player. 
${ }^{33}$ Ibid.

${ }^{34}$ Department of Planning, Monitoring and Evaluation. "Documents". 2019. < $\underline{\text { https:// }}$ www.operationphakisa.gov.za/operations/oel/pmpg/MPGPerformance/Pages/default.aspx $>$ Accessed on 10 March 2019.

${ }^{35}$ P Pretorius. "The implications of comprehensive and incremental approaches to public sector reform for the creation of a developmental state in South Africa: Case study of the Oceans Economy Operation Phakisa". Unpublished MA thesis. University of Cape Town, 2018, 62.

${ }^{36} \mathrm{P}$ Shemella. "Introduction". In Shemella, P (ed), Global responses to maritime violence: Cooperation and collective action. Stanford: Stanford University Press, 2016, 2.

${ }^{37}$ One Earth Future. Stable Seas Progamme. Maritime Security Index. https://stable seas.org/issue-areas/overview> Accessed on 16 March 2020.

${ }^{38} \mathrm{R}$ Rotberg. "The governance of nations: Definitions and measures". In Rotberg, R (ed), On governance: What it is, what it measures, and its policy uses. Waterloo: Center for International Governance Innovation, 2015, 15.

${ }^{39}$ C Bueger \& T Edmunds. "Beyond sea blindness: A new agenda for maritime security studies". International Affairs 93/6. 2017. 1300-1301.

${ }^{40}$ Share op. cit.

${ }^{41} \mathrm{H}$ Wassermann. "Everything you need to know about South Africa's massive gas find". Business Insider South Africa. 15 February 2018. <https://www.businessinsider.co.za/impact-of-brulpadda-2019-2 $>$ Accessed on 17 February 2019.

${ }^{42}$ Bowmans. "Stowaways activity increases in Port of Durban". 12 February 2017. $<$ https://www.bowmanslaw.com/insights/shipping-and-logistics/stowaways-activity-increases-port-durban/> Accessed on 5 February 2019.

${ }^{43}$ DO Obura. "Ocean health in the blue economy". In Attri \& Bohler-Muller op. cit., p. 412.

${ }^{44}$ The Presidency. Address by His Excellency President Jacob Zuma at the Operation Phakisa: Unlocking the Economic Potential of the Ocean Economy Open Day, International Convention Centre, Durban, 15 October 2015, 6-7.

${ }^{45}$ Share op. cit.

${ }^{46}$ A Roy. Blue economy in the Indian Ocean. Occasional paper no. 181. New Delhi: Observer Research Foundation, January 2019, 6.

${ }^{47}$ Findlay op. cit., pp. 248-249.

${ }^{48} \mathrm{~K}$ Sink. "The marine protected areas debate: Implications for the proposed Phakisa Marine Protected Areas Network". South African Journal of Science 112/9 \& 10. 2016. 2-3.

49 The Presidency. Address by His Excellency President Jacob Zuma on progress made in respect of the Operation Phakisa: Oceans economy initiatives, Port Elizabeth, 8 April 2016. 
${ }^{50}$ D Masie \& P Bond. "Eco-capitalist crisis in the blue economy: Operation Phakisa's small slow failures". In Satgar, V (ed), The climate crisis. South African and global democratic eco-socialist alternatives. Johannesburg: Wits University Press, 2018, 320.

${ }^{51}$ Ibid., p. 325.

${ }^{52}$ Ibid., p. 315.

${ }^{53}$ Ibid., pp. 317-318.

${ }^{54} \mathrm{P}$ Shemella. "Integrated strategies against maritime violence". In Shemella op. cit., p. 77.

${ }^{55}$ Republic of South Africa. Operation Phakisa. Oceans Economy Summary Report. September 2017. < https:/www.environment.gov.za/sites/default/files/docs/ publications/oceanseconomy_summaryreport.pdf $>$ Accessed on 15 March 2020.

${ }^{56}$ Parliamentary Monitoring Committee. "Policing of small harbours". SAPS presentation to the Department of Agriculture, Forestry and Fisheries. 2018.

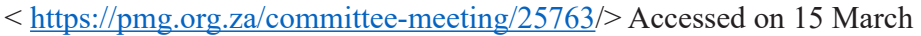
2020.

${ }^{57}$ Damen Shipyards Cape Town. "DSCT will deliver three Inshore Patrol Vessels for the South African Navy". 26 February 2018. <https://www. damen.com/en/news/2018/02/damen shipyards cape town dsct receives project biro_order_from_armscor> Accessed on 20 February 2019.

${ }^{58}$ Engel op. cit., p. 60.

${ }^{59}$ Since late 2019 renamed Department of Environment Forestry and Fisheries (DEFF).

${ }^{60} \mathrm{Ibid}$., p. 66.

${ }^{61}$ Pretorius op. cit., p. 72.

${ }^{62}$ Department of International Relations and Cooperation. Annual Performance Plan. Part A: Strategic overview. 2018-2019, 10.

${ }^{63}$ Bohler-Muller op. cit., p. 237.

${ }^{64}$ Engel op. cit., p. 64.

${ }^{65}$ Bohler-Muller op. cit., p. 243.

${ }^{66}$ Ibid., p. 244.

${ }^{67}$ Pretorius op. cit., p. 54.

${ }^{68}$ Ibid., pp. 31-34.

${ }^{69}$ Ibid., pp. 45-51.

${ }^{70}$ Ibid., p. 77. 